\title{
Neonatal Hypothyroxinemia: Effects of Iodine Intake and Premature Birth*
}

\author{
SUSANA ARES, HÉCTOR F. ESCOBAR-MORREALE, JOSÉ QUERO, \\ SOCORRO DURÁN, MARÍA JESUS PRESAS, RAFAEL HERRUZO, AND \\ GABRIELLA MORREALE DE ESCOBAR
}

\begin{abstract}
Unidad de Neonatología, Hospital La Paz, Instituto Nacional de Salud (S.A., J.Q.); and Unidad de Endocrinología Molecular, Instituto de Investigaciones Biomédicas y Facultad de Medicina, Consejo Superior de Investigaciones Científicas and Universidad Autónoma (H.F.E.-M., S.D., M.J.P.,

G.M.d.E.); and Unidad de Medicina Preventiva, Facultad de Medicina de la Universidad Autónoma (R.H.), Madrid, Spain
\end{abstract}

\begin{abstract}
We have investigated the effects of iodine (I) intake on urinary I excretion in preterm (PT) babies up to 2 months after birth and its effect on serum $\mathrm{T}_{4}$, free $\mathrm{T}_{4}\left(\mathrm{FT}_{4}\right), \mathrm{T}_{3}, \mathrm{TSH}$, and thyroglobulin $(\mathrm{Tg})$ levels compared to those in term (T) newborns.

Very premature and very sick infants were in negative I balance for the first weeks after birth. Later, these same infants, as well as the other PT and T newborns, were in positive balance; $75-80 \%$ of the ingested I was not accounted for in the urine. The urinary I levels of $\mathrm{PT}$ and $\mathrm{T}$ neonates cannot be equated to their I intakes.

$\mathrm{T}_{4}, \mathrm{FT}_{4}$, and $\mathrm{T}_{3}$ levels in $\mathrm{PT}$ and $\mathrm{T}$ neonates increased with post-
\end{abstract}

menstrual age, whereas Tg decreased and TSH did not change. Serum $\mathrm{FT}_{4}, \mathrm{~T}_{3}, \mathrm{Tg}$, and TSH levels in PT neonates were affected negatively, independently from age, by a low I intake. PT birth also affected $\mathrm{T}_{4}$, $\mathrm{FT}_{4}$, and $\mathrm{Tg}$ negatively, independently from I intake and postmenstrual age, for at least $6-8$ weeks after birth.

Care should be taken to avoid I deficiency in PT neonates. However, even when I intake is adequate, PT newborns are hypothyroxinemic compared to $\mathrm{T}$ babies during an important period of brain development. This suggests the possible convenience of interventions that might mimic the intrauterine hormone environment and accelerate maturation. (J Clin Endocrinol Metab 82: 1704-1712, 1997)
$\mathrm{D}$ URING THE first half of gestation, thyroid hormone available to the fetus is predominantly of maternal origin (1). Once fetal thyroid secretion starts, fetal supplies are of mixed fetal and maternal origin. Although fetal thyroidal secretion is believed to constitute an increasing proportion of the hormone available to the developing fetus, maternal transfer of $\mathrm{T}_{4}$ may still contribute significantly to fetal needs (20-50\% of normal values) up until term (2), mitigating the consequences of an inadequate fetal thyroid function (3). Although the capacity to synthesize thyroglobulin ( $\mathrm{Tg})$, to concentrate iodine (I), and to synthesize $\mathrm{T}_{4}$ and $\mathrm{T}_{3}$ may start earlier, secretion of iodinated hormones by the fetal thyroidal is believed to start at midgestation, when hypothalamic-pituitary circulation matures, and TSH is secreted into the fetal blood $(4,5)$. As shown in fetal serum obtained in utero by cordocentesis $(6,7), \mathrm{T}_{4}$ and free $\mathrm{T}_{4}\left(\mathrm{FT}_{4}\right)$ do not clearly increase until 20-24 weeks gestation, and free $\mathrm{T}_{3}\left(\mathrm{FT}_{3}\right)$ is mostly undetectable until after 32 weeks. Thus, the earlier in pregnancy, the more immature the fetal gland and the more important the proportion of fetal requirements that are met by the maternal contribution of hormone. Fetal thyroidal secretion has barely started in

Received December 31, 1996. Revision received February 5, 1997. Accepted March 10, 1997.

Address all correspondence and requests for reprints to: Dr. G. Morreale de Escobar, Instituto de Investigaciones Biomédicas, Facultad de Medicina Universidad Autónoma de Madrid, Arzobispo Morcillo 4 , 28029 Madrid, Spain. E-mail gmorreale@mvax.fmed.uam.es.

* This work was supported by the Heinz-Koch Foundation (Milupa, Spain) and the Fondo de Investigaciones Sanitarias (FIS Grant 92/0888 and Fellowship 92/5351 to S.A.). premature neonates of 24 weeks gestational age (GA) and has been contributing to fetal requirements for only a few weeks in those born at 27 weeks GA, compared to 3 months in term ( $\mathrm{T})$ babies.

Preterm (PT) babies have low circulating levels of $\mathrm{T}_{4}$ and $\mathrm{FT}_{4}(8)$; the degree of hypothyroxinemia is greater in the very premature neonates (9). For years their alterations in circulating parameters of thyroid function have been considered an expression of their physiological hypophyseal-pituitarythyroid immaturity or a manifestation of nonthyroidal illness, but 2 recent follow-up studies of $640 \mathrm{PT}$ children up to 5 and 9 yr of age (10) and of 400 premature infants up to 2 yr of age (11) have confirmed that severe hypothyroxinemia plays an important causative role in their frequently impaired mental development and disabling cerebral palsy.

Worldwide, the most frequent cause of hypothyroxinemia is I deficiency, which is at present recognized as the major cause of preventable mental retardation throughout the world and a major cause of disabling cerebral palsy. The severity of the damage is not only related to the degree of the deficiency, but also to the developmental phase during which it is suffered, the most severe being the consequence of I deficiency during the first two trimesters of pregnancy $(12,13)$. The I intake of the mother ought to ensure that her thyroid synthesizes enough hormone for her needs and those of the developing fetus as well as an adequate supply of I for fetal and neonatal thyroid function, both in utero and during lactation. An inadequate I supply might be especially dangerous in the case of PT babies, who have been prematurely deprived not only of the maternal supply of hormone, but 
also of I, before their own glands have been able to accumulate as much I as in T newborns.

This lead us to investigate the I content of formula preparations used for premature infants and for T neonates (14). The present study investigates the role of I intake on the thyroid function of PT infants. It reports the relationship between I intake and urinary I excretion in PT neonates at different postmenstrual ages (PMA) ${ }^{1}$ and compares the results with those of $\mathrm{T}$ neonates. It also investigates whether their circulating thyroid hormone levels would reach the same values as those of $\mathrm{T}$ neonates once their I intakes become comparable. As will be seen, although a higher I intake results in an amelioration of several circulating parameters of thyroid function, a certain degree of hypothyroxinemia persists for months, even if I intake is comparable to that of newborn neonates.

\section{Subjects and Methods}

\section{Patients}

As part of a study on thyroid function of premature babies, we determined the I intake and I excretion of 115 premature and 28 healthy $\mathrm{T}$ infants born in the Neonatology Unit of the Hospital La Paz (Madrid, Spain). The premature infants, born between 27-36 weeks GA (body weights ranging from 900-4200 g), were studied during the first week of life and every 15 days for up to $2-4$ months after birth. The T infants, born between 37-42 weeks GA, were followed for a shorter period, up to 1-1.5 months. During the study period I-containing topical antiseptics were banned from the Neonatology Unit. Infants exposed to external sources of I as a result of radiological or surgical examinations were excluded from the study as were those receiving parenteral feeding, because an I-containing contrast medium had been used to position the catheters (15). The study was approved by the ethics committee of the Hospital La Paz.

There were 15 PT infants of 27-30 weeks GA, but only the data obtained for 10 of them before the onset of parenteral feeding are included in the present study as well as all data from the 5 infants who were always fed orally. Of the 31-36 weeks GA PT babies included in the study, 52 were healthy; there were 9 small for GA (SGA) infants, and 35 were considered sick PTs with different pathologies, mostly hyaline membrane disease, transitory distress syndrome, severe infection, cardiovascular abnormalities, anemia, persistent ductus arteriosus, intracranial hemorrhage, and perinatal hypoxia.

On each occasion, samples of the different formulas or maternal milk given to each baby were kept for the direct determination of I content, and the ingested volume over a 24 -h period was recorded in each case, as described previously in more detail (14). The 24-h urine was collected at each study period for the determination of I and creatinine concentrations. Venous blood samples were withdrawn for the determination of $\mathrm{TSH}$, total $\mathrm{T}_{4}, \mathrm{FT}_{4}, \mathrm{~T}_{3}$, and $\mathrm{Tg}$. When the blood volume obtained was too small for all of the determinations, only $\mathrm{FT}_{4}, \mathrm{~T}_{3}$, and $\mathrm{Tg}$ were measured.

\section{I determinations}

The concentration of I in formula and milk samples was determined by a modification of the method described by Benotti and Benotti (16) for serum, with duplicate $40-\mu \mathrm{L}$ aliquots of each preparation being digested in $2 \mathrm{~mL}$ chloric acid. The inter- and intraassay coefficients of variation were $14.7 \pm 6.7 \%( \pm \mathrm{SD})$ and $12.5 \pm 1.8 \%$, respectively. The concentration of $\mathrm{I}$ in the urine was determined using $0.5-\mathrm{mL}$ aliquots and $3 \mathrm{~mL}$ chloric acid. This method determines the total I content of milk and urine regardless of its initial chemical form.

\section{Thyroid function tests}

Serum TSH (Dynotest TSH from Henning Berlin, Berlin, Germany) $\mathrm{T}_{4}$ and $\mathrm{T}_{3}$ (RIA kit from Clinical Assays, Baxter, Cambridge, MA), and

${ }^{1}$ PMA is the GA plus the postnatal age, in weeks.
$\mathrm{FT}_{4}$ (Two Step Gammacoat Free $\mathrm{T}_{4}$ RIA kit from Clinical Assays) concentrations were measured in duplicate by specific RIAs. Tg was measured by immunoradiometric assay (Dynotest Tg from Henning Berlin).

\section{Statistical analysis}

Mean values $( \pm$ SEM) are shown. Data were subjected to one-way ANOVA after testing for homogeneity of variance. The significance of the difference between groups was identified by the Newman-Keuls test for multiple comparisons. All calculations were performed as described by Snedecor and Cochran (17). Multiple regression and partial correlation analyses were performed using the SPSS program (SPSS Inc., Chicago, IL).

Whenever it is stated that a certain variable was higher or lower for different groups or that correlations existed between the variables, it is implicit that the differences or correlation coefficients were statistically significant, at $P<0.05$ or less.

\section{Results}

\section{I intake}

The I intake is calculated from the I concentration of the formula or maternal milk, which we have previously reported in detail (14), and the volume ingested.

The volume of milk ingested during a 24-h period by all the PT and T babies at different PMA, corrected for differences in body weight, is shown in Fig. 1. The very small premature babies did not ingest the $150-200 \mathrm{~mL} / \mathrm{kg}$ BW·day recommended for $\mathrm{T}$ babies (18) until they were approximately 1 month old and weighed $2 \mathrm{~kg}$ or more.

Figure 2 shows the I intake of all PT and T infants at different PMA. As a consequence of the small volume of milk ingested, the I intake of the 27-30 weeks GA infants and that of all sick and SGA infants were lower during the first week of life (7.5 $\pm 1.8 \mu \mathrm{g}$ I/day) than that of the healthy PT babies $(16.5 \pm 1.6 \mu \mathrm{g} \mathrm{I} /$ day). The corresponding values at 1 month of age were, respectively, $13.1 \pm 2.2 \mu \mathrm{g}$ I/day (27-30 weeks GA and sick neonates), $19.3 \pm 2.5 \mu \mathrm{g}$ I/day (SGA neonates), and $25.1 \pm 2.8 \mu \mathrm{g} \mathrm{I} /$ day (T neonates). The differences disappeared at later ages.

\section{I excretion into urine}

Urinary I excretion was calculated from the volume and the I concentration of the 24-h urine sample. We obtained data for urinary I concentration in 182 samples, but reliable 24-h urine collection was not always successful. This reduced

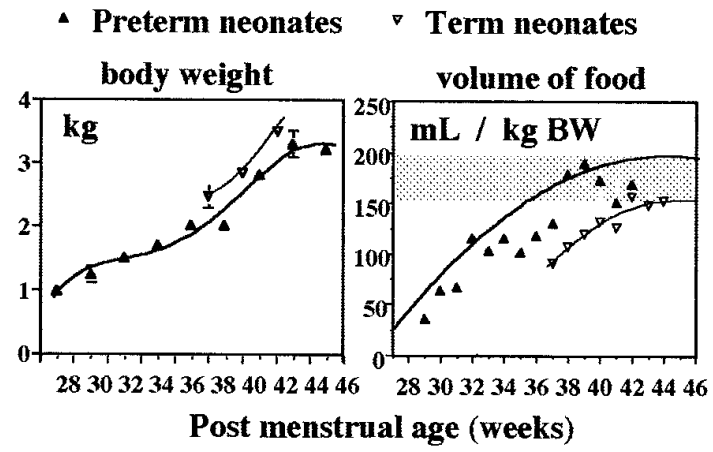

FIG. 1. The left panel shows the mean ( \pm SEM) body weights of PT and $\mathrm{T}$ neonates in the present study at different PMA. The right panel shows the volumes of daily ingested formula or milk in reference to body weight. The shaded area corresponds to the volume of 150-200 $\mathrm{mL} / \mathrm{kg}$ BW usually recommended as normal for neonates (18). 
the daily I excretion data to 86 values, from 69 PT and $28 \mathrm{~T}$ infants. The volume of urine was correlated to both the body weight of the PT baby and the PMA, and the data were fitted $(P<0.02)$ by the following equation: volume of urine $(\mathrm{mL} /$ day) $=162-3.6 \times$ PMA $+29.7 \times$ BW, where the PMA is given in weeks and the body weight in kilograms.

The mean volume of urine was $46.7 \pm 2.4 \mathrm{~mL} / \mathrm{kg}$ BW $\cdot$ day for PT neonates and $33.5 \pm 4.6 \mathrm{~mL} / \mathrm{kg} \mathrm{BW} \cdot$ day for T infants. These values are within the normal ranges given by others for both PT and T infants (18). The volume of urine (in milliliters per $\mathrm{kg} \mathrm{BW}$ ) decreased with PMA in the PT infants, whereas no age-related change was observed in T neonates.

The pattern of 24-h urinary I excretion is shown for PT and $\mathrm{T}$ babies in Fig. 2. During the first weeks of life (see the inset of Fig. 2), I excretion was higher in the majority of the 27-30 weeks GA babies than in the same babies at later postnatal ages. On the contrary, I excretion in PT infants of 31-36 weeks GA increased with PMA and, to a lesser degree, with I intake. When the results were grouped according to PMA and/or the presence of illness, it was observed that the 27-33 weeks PMA sick infants excreted approximately 1.5 times the amount of I into the urine as healthy $\mathrm{T}$ babies despite their lower I intake.

\section{I excretion vs. intake}

Figure 2 compares the urinary I excretion with the intake for both PT and T infants. Initially (Fig. 2, inset), the mean I excretion was usually higher than the intake, but starting at about 31-32 weeks PMA, the mean urinary I excretion was lower than the intake. The differences increased markedly with age.

When urinary I excretion was plotted against the daily intake (not shown), it was observed that the majority of PT babies excreted much less I than they ingested. The 24-h I intake and urinary excretion were positively correlated, but with a regression coefficient $(n=74 ; r=0.35)$ that, although

\section{Intake : Preterm Excretion : Preterm}

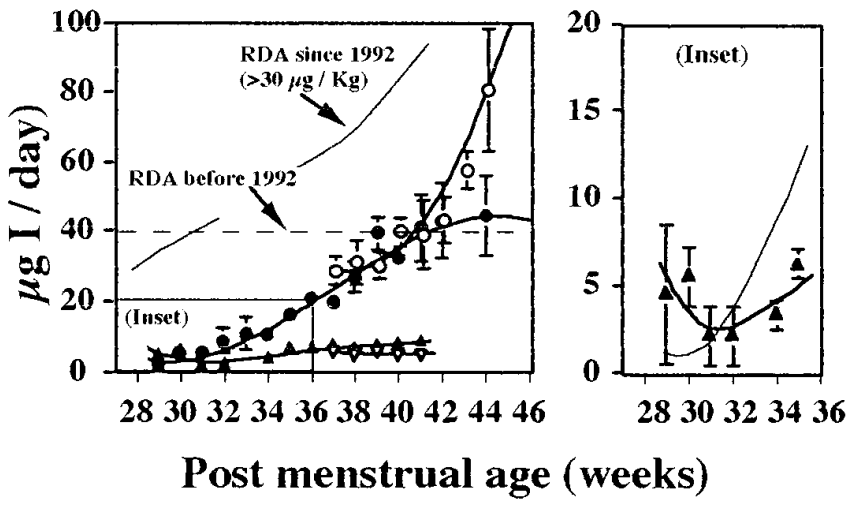

FIG. 2. The mean $( \pm$ SEM $)$ daily I intake and excretion of PT and T neonates are shown as a function of PMA. The dashed horizontal line indicates the recommended daily allowance defined before 1992; the more recent recommendation (19) of more than $30 \mu \mathrm{g} / \mathrm{kg} \cdot \mathrm{day}$ is also shown as a thin curve. The inset amplifies the urinary I excretion data between 29-35 weeks PMA. The corresponding I intake is shown as a thin curve. statistically significant, was relatively poor for estimation of I intake from the 24-h urinary excretion data. When the more numerous data of urinary I concentration $(n=182)$ were considered instead of the 24-h excretion, and PMA and body weight were also taken into account, the data fitted the following equation $(P<0.001)$ : I intake $(\mu \mathrm{g} /$ day $)=-74.9+$ $2.02 \times$ PMA $+8.2 \times \mathrm{BW}+63.7 \times$ urinary $\mathrm{I}(\mu \mathrm{g} / \mathrm{mL})$.

To test how far the I intakes might be assessed from the above equation when the 24-h collection was incomplete and only the urinary I concentration was known, we performed a paired $t$ test comparing the actual measured intakes $(21.1 \pm$ $1.7 \mu \mathrm{g} \mathrm{I} /$ day) with the calculated ones $(21.1 \pm 1.1 \mu \mathrm{g} \mathrm{I} /$ day $)$; no difference was found. When this equation was applied to the $\mathrm{T}$ newborns, up to 1.5 months of age there was no difference between the measured intakes $(38.0 \pm 4.2 \mu \mathrm{g} /$ day $)$ and the calculated intake values $(37.8 \pm 2.2 \mu \mathrm{g} /$ day $)$, suggesting that during this neonatal period the above equation might also be used to estimate the I intake. This equation should be considered as merely tentative, as we do not know whether it would be valid for PT infants receiving a much higher or lower I intake than those reported in the present study, in which the maximum I intake was $90 \mu \mathrm{g} /$ day.

\section{Urinary creatinine}

The mean urinary creatinine concentration of PT infants was lower $(7.2 \pm 0.4 \mathrm{mg} / \mathrm{dL})$ than that of T newborns $(13.0 \pm$ $3.6 \mathrm{mg} / \mathrm{dL} ; P<0.001)$. No reliable correlation was found between the urinary creatinine concentration and PMA, body weight, or body length in either PT or T babies. When the creatinine concentrations were used to calculate the I to creatinine ratios, the previous correlations between urinary I concentration and I intake, PMA, and body weight were not improved, but were actually weakened.

\section{I balance}

The daily I balance was calculated as the difference between the I intake and the I excretion. As evident from the data shown in Fig. 2, the I balance of very premature infants appeared to be negative, whereas at about 31-32 weeks of PMA and later, the I balance was clearly positive. For this

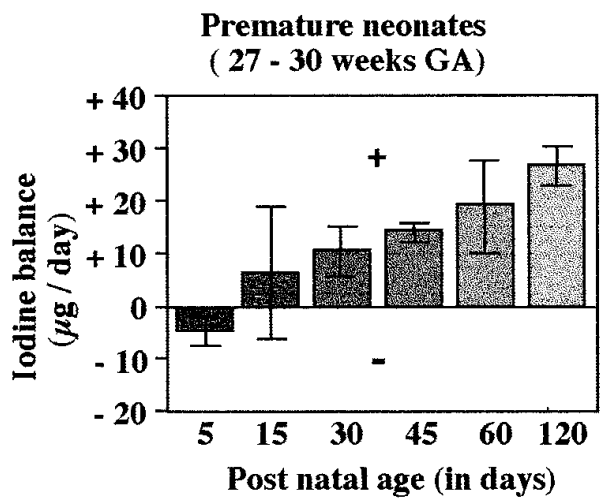

FiG. 3. Mean ( \pm SEM) I balance of 27-30 weeks GA neonates at different postnatal ages. The mean I balance was negative $(-)$ in practically all neonates for the first week after birth, but became positive $(+)$ in practically all of them by 1 month of age. 
TABLE 1. Percentage of preterm and term neonates in negative balance

\begin{tabular}{|c|c|c|c|c|c|c|}
\hline \multirow{3}{*}{$\begin{array}{l}\text { Postnatal } \\
\text { age (days) }\end{array}$} & \multicolumn{5}{|c|}{ Group by GA (weeks) } & \multirow{3}{*}{ Term } \\
\hline & \multirow{2}{*}{$27-30$} & \multicolumn{2}{|c|}{$31-33$} & \multicolumn{2}{|c|}{$34-36$} & \\
\hline & & Sick & Healthy & Sick $^{a}$ & Healthy & \\
\hline 5 & 75 & 28 & 11 & 21 & 11 & 7 \\
\hline 30 & 0 & 0 & 0 & 0 & 0 & 0 \\
\hline
\end{tabular}

Percentages were calculated using as $100 \%$ the number of infants in each group with complete 24-h urine excretion data.

${ }^{a}$ The SGA infants are included in this subgroup.

reason, the results of these different groups are described separately.

\section{Negative I balance}

As indicated above, the very immature, 27-30 weeks PMA PTs showed a different pattern of I balance than the 31-36 weeks PMA healthy PTs; most of the former group were in negative balance during the first week of life. This negative balance was greater the more immature the PT baby. As illustrated in Fig. 3, this condition was only transient, with the balance changing from negative to positive with increasing PMA.

Many of the 31-36 weeks GA PT infants who were sick and many of the SGA neonates also excreted more I into the urine for the first weeks of life than healthy babies of the same PMA, as summarized in Table 1, despite the fact that their I intake was not higher.

When the data from all 17 PT babies in negative balance were considered as a whole, it was found that a negative balance was more frequent for the first days of postnatal life (9.0 \pm 1.6 days) when their mean GA was $32.5 \pm 0.7$ weeks and their mean weight was less than $2.0 \mathrm{~kg}(1.9 \pm 0.2 \mathrm{~kg})$. The negative I balance of these babies decreased with their PMA and body weight. The urinary I excretion of the PT neonates who were in negative balance increased with their I intake. This finding suggests that the premature infants in negative balance are unable to retain all the I they are ingesting, and that an increased intake would not correct their negative I balance.

When the volumes of urine of all PTs in negative balance were compared to those of PMA-matched PT babies in positive I balance, it was observed that the volume of urine excreted by the former $(102 \pm 8 \mathrm{~mL} /$ day $)$ was higher than that in the PT neonates in positive balance $(73 \pm 9 \mathrm{~mL} /$ day $)$. The negative I balance of these PT babies was not related to corticosteroid treatment of the mothers at risk of premature delivery.

\section{Positive I balance}

Most of the 31-36 weeks GA healthy PT infants and T babies were in positive I balance (Table 1), which increased with I intake and, to a lesser degree, with PMA. As I intake was also correlated to PMA, multiple regression analysis was performed to assess the relative contributions of both variables to I balance. I intake proved to be the major factor influencing I balance regardless of the stage of maturation, as measured by PMA.

The urinary I excretion was positively correlated to the I

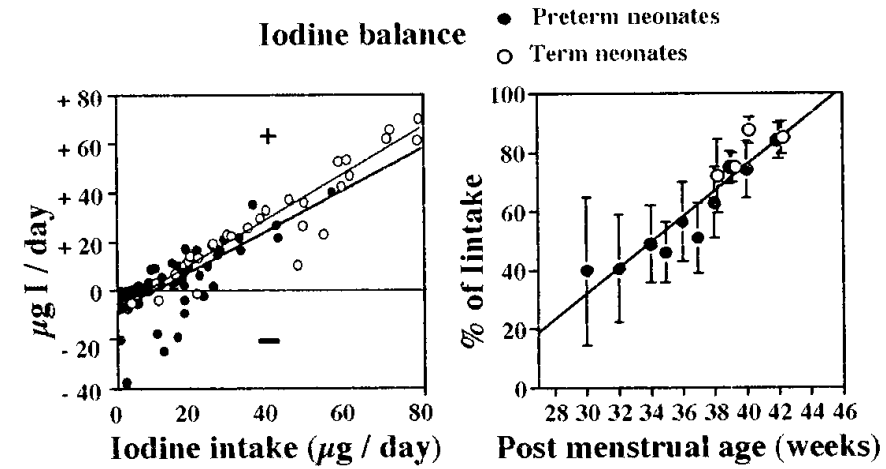

FIG. 4. Left panel, Individual values for I balance in both PT and T neonates are plotted against their I intakes. When, regardless of PMA and body weight, the I intake was the same, there was no statistically significant difference between the I balances of PT and T neonates. Right panel, The positive I balance after 30 weeks PMA is expressed as a percentage (mean \pm SEM) of the I intake and shown as a function of PMA for both PT and T neonates.

intake, as indicated for immature infants in negative balance, but the slope of the linear function was much lower than that obtained for premature infants in negative balance.

\section{Comparisons between PT and T babies}

I balance. Figure 2 not only shows the I intake and urinary I excretion of PT babies but also those of T infants during their first 6 weeks after birth. To correct for differences in PMA between the PT and T neonates, I balance was plotted against I intake (Fig. 4, left panel). No differences were found between the linear regressions for PT vs. T infants. This indicates that when I intake is the same, the amount of I that is retained by the PT infant is the same as that retained by T infants. The right panel of Fig. 4 shows the positive I balances of the premature and full-term neonates as a percentage of their I intakes and as a function of PMA. As may be seen, the capacity to retain the ingested I was not constant, but increased with PMA. There was also a great individual variability around the mean value for a given PMA in the capacity to retain the ingested I, which was greater the younger the neonate.

Parameters of thyroid function. As evident from the upper panels of Fig. 5, the age-related changes in circulating parameters of thyroid function were different in PT and T infants. The circulating $\mathrm{T}_{3}, \mathrm{~T}_{4}$, and $\mathrm{FT}_{4}$ levels in the PT infants increased, whereas Tg levels decreased, as functions of PMA. On the contrary, in the $\mathrm{T}$ neonates described here we found that circulating $\mathrm{T}_{3}$ hardly changed with increasing PMA, whereas 
- Preterm neonates

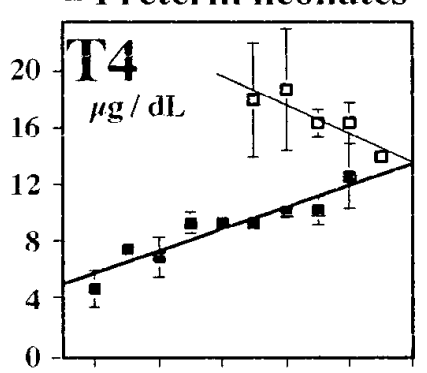

$\square$ Term neonates
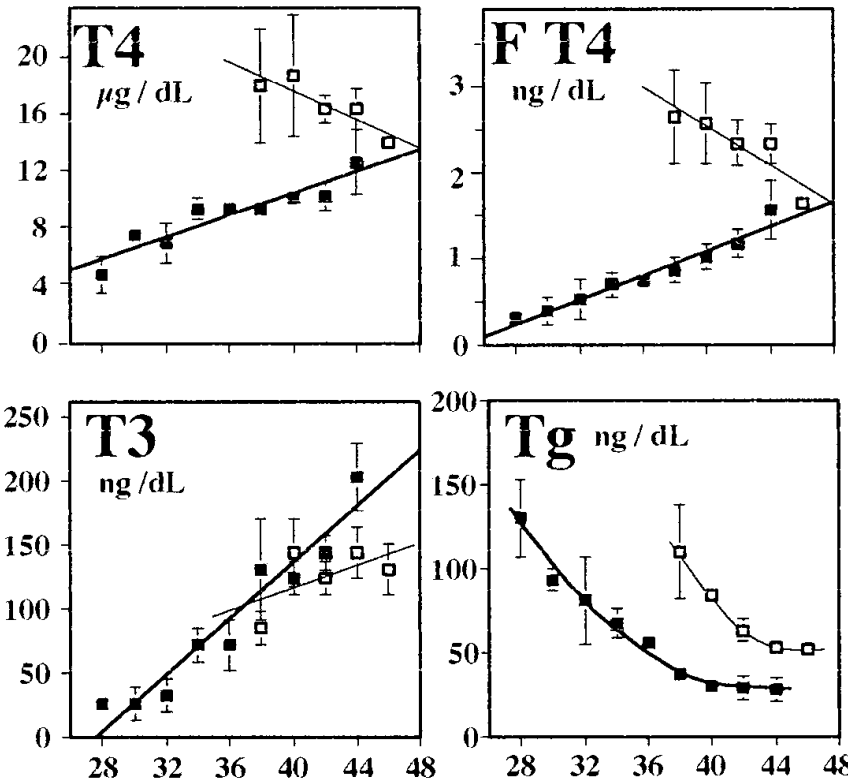

Post menstrual age (weeks)

FIG. 5. Mean ( \pm SEM) circulating concentrations of $\mathrm{T}_{4}, \mathrm{FT}_{4}, \mathrm{~T}_{3}$, and $\mathrm{Tg}$ are plotted against PMA for both PT and T neonates.

- Preterm neonates
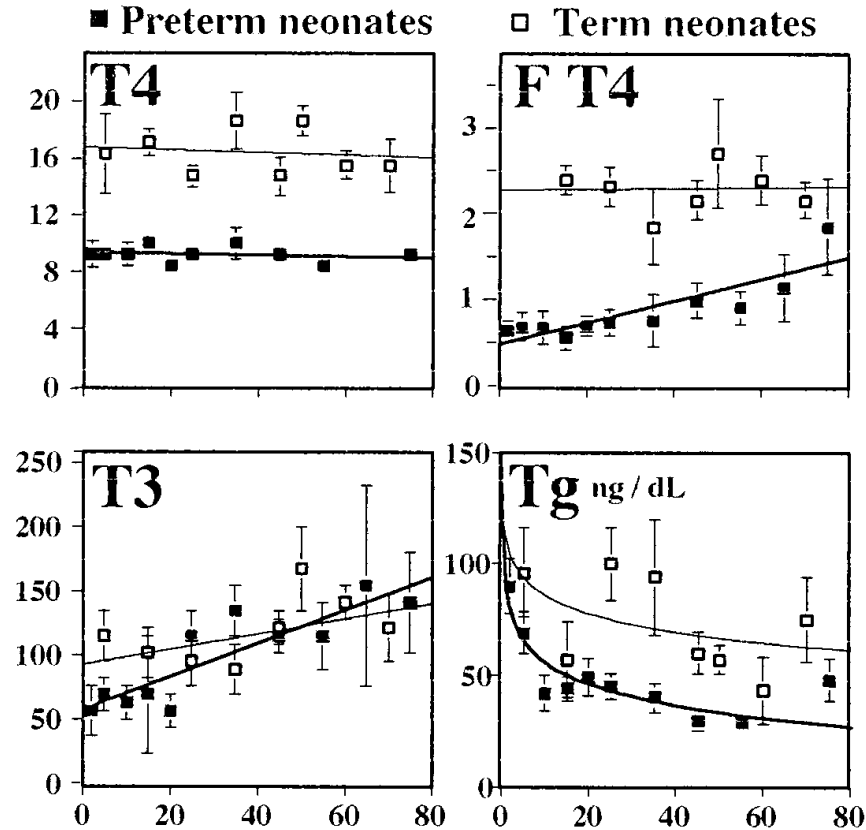

Iodine intake ( $\mu \mathrm{g} /$ day)

FIG. 6. Mean ( \pm SEM) circulating concentrations of $\mathrm{T}_{4}, \mathrm{FT}_{4}, \mathrm{~T}_{3}$, and $\mathrm{Tg}$ are plotted against the daily I intake for both $\mathrm{PT}$ and $\mathrm{T}$ neonates.

$\mathrm{T}_{4}, \mathrm{FT}_{4}$, and $\mathrm{Tg}$ decreased. Serum $\mathrm{TSH}$ (not shown) decreased during the first week after birth in both PT and T neonates, but did not later correlate with age.

Figure 6 shows the possible relationship between circulating parameters of thyroid function and I intake. $\mathrm{T}_{4}$ was not related to I intake in either PT or T infants. TSH (not shown),
$\mathrm{FT}_{4}$, and $\mathrm{T}_{3}$ were correlated with $\mathrm{I}$ intake in PT, but not $\mathrm{T}$, neonates. Circulating $\mathrm{Tg}$ decreased with I intake in both groups. Results were quite similar when these variables were plotted against the calculated I balance.

It, therefore, appeared of interest to assess whether circulating parameters of thyroid function in premature neonates would be comparable to those in $\mathrm{T}$ infants when their I intakes (and balance) were the same.

As I intake was also affected by PMA (Fig. 2), it appeared important to exclude the influence of PMA on the relationships illustrated in Fig. 6. Partial correlation analysis was performed using only the data from those cases without any missing variable; all cases where one or more variables were missing were omitted from the study. This avoided uneven weights of variables due to differences in the number of data. We also omitted the data from very sick infants to avoid hormone alterations that might be a consequence of the neonatal pathology. This stringency reduced the study to 90 cases. As summarized in Table 2, this partial correlation analysis indicated that some of the circulating parameters of thyroid function were correlated to I intake independently from PMA; results were different for PT and $\mathrm{T}$ neonates (Table 2). In PT babies, the circulating levels of $\mathrm{T}_{3}, \mathrm{FT}_{4}, \mathrm{Tg}$, and TSH were indeed related to I intake, independently of PMA. On the contrary, the only circulating parameter of thyroid function that appeared to be related to the I intake in $\mathrm{T}$ babies was the serum concentration of $\mathrm{Tg}$, which decreased with increasing intake.

Figure 6 also shows that differences persisted between PT and $\mathrm{T}$ infants in the circulating levels of $\mathrm{T}_{4}, \mathrm{FT}_{4}$, and $\mathrm{Tg}$, even when I intakes were the same. To evaluate the influence of PT vs. T birth, a multiple regression analysis was performed. The variables were I intake and circulating $\mathrm{T}_{4}, \mathrm{FT}_{4}, \mathrm{~T}_{3}, \mathrm{Tg}$, and TSH; PT or T birth was the qualitative condition separating the data into two groups. When PMA was also entered among the variables, the conclusions were comparable. The results are summarized in Table 3 and show that being born prematurely is the main factor responsible for the lower circulating levels of $\mathrm{T}_{4}, \mathrm{FT}_{4}$, and $\mathrm{Tg}$ and persists even when I intakes are comparable.

This does not mean that parameters of thyroid function are not ameliorated by increasing the I intake of PT babies, as their circulating $\mathrm{T}_{3}, \mathrm{FT}_{4}, \mathrm{Tg}$, and TSH levels are improved with higher I intakes independently of PMA, as apparent from Table 2 and in agreement with our previous report (14) in which I intake of PT neonates above or below $40 \mu \mathrm{g} \mathrm{I} /$ day was used as the qualitative condition separating the data for covariance analysis.

Comparisons between premature babies and fetuses in utero. We have compared the present findings to those obtained in utero by cordocentesis (7). The result for $\mathrm{FT}_{4}$ is shown in Fig. 7. As may be seen, the $\mathrm{FT}_{4}$ of premature infants was clearly below the $95 \%$ confidence interval of the values given for fetuses of the same age in utero. It is unlikely that this is related to methodological differences between the two different laboratories, as the $\mathrm{FT}_{4}$ levels of the $\mathrm{T}$ neonates in the present study were not lower than those reported by Thorpe-Beeston et al. (7). Although not shown here, we also found that the circulating TSH levels of both the PT and T neonates were 
TABLE 2. Partial correlation analysis: regression coefficients (r) and significance $(P)$

\begin{tabular}{|c|c|c|c|c|c|}
\hline & $\mathrm{T}_{3}$ & $\mathrm{~T}_{4}$ & Free $T_{4}$ & $\mathrm{Tg}$ & TSH \\
\hline \multicolumn{6}{|l|}{ Preterm babies } \\
\hline Postmenstrual age $v s$ & $\begin{array}{l}\mathrm{r}=0.28 \\
P<0.01\end{array}$ & $\begin{array}{l}\mathrm{r}=0.17 \\
P<0.05\end{array}$ & $\begin{array}{l}\mathrm{r}=0.8 \\
P<0.01\end{array}$ & $\begin{array}{l}\mathrm{r}=-0.96 \\
P<0.001\end{array}$ & NS \\
\hline Iodine intake $v s$. & $\begin{array}{l}\mathrm{r}=0.3 \\
P<0.001\end{array}$ & $\mathrm{NS}^{a}$ & $\begin{array}{l}\mathrm{r}=0.8 \\
P<0.001\end{array}$ & $\begin{array}{l}\mathrm{r}=-0.3 \\
P<0.001\end{array}$ & $\begin{array}{l}\mathrm{r}=-0.3 \\
P<0.05\end{array}$ \\
\hline \multicolumn{6}{|l|}{ Term babies } \\
\hline Postmenstrual age $v s$. & $\begin{array}{l}\mathrm{r}=0.58 \\
P<0.05\end{array}$ & $\begin{array}{l}\mathrm{r}=-0.9 \\
P<0.01\end{array}$ & $\begin{array}{l}\mathrm{r}=-0.75 \\
P<0.01\end{array}$ & $\begin{array}{l}\mathrm{r}=-0.87 \\
P<0.01\end{array}$ & NS \\
\hline Iodine intake $v s$. & NS & NS & NS & $\begin{array}{l}\mathrm{r}=-0.34 \\
P<0.05\end{array}$ & NS \\
\hline
\end{tabular}

${ }^{a} \mathrm{NS}=$ not statistically significant.

TABLE 3. Multiple linear regression analysis: effect of premature or term birth on circulating $\mathrm{T}_{4}, \mathrm{FT}_{4}$, and $\mathrm{Tg}$ concentrations

\begin{tabular}{llcc}
\hline Variable & $\begin{array}{c}\text { Effect of } \\
\text { prematurity }\end{array}$ & $\begin{array}{c}\text { 95\% Confidence } \\
\text { interval }\end{array}$ & $P$ \\
\hline $\mathrm{T}_{4}$ & $80.1 \mathrm{nmol} / \mathrm{L}$ lower & $60-100$ & $<0.001$ \\
$\mathrm{FT}_{4}$ & $20.9 \mathrm{nmol} / \mathrm{L}$ lower & $18-26$ & $<0.001$ \\
$\mathrm{Tg}^{a}$ & $46.0 \mathrm{ng} / \mathrm{dL}$ lower & $28-64$ & $<0.001$ \\
\hline
\end{tabular}

${ }^{a}$ Linearity was obtained after logarithmic transformation.

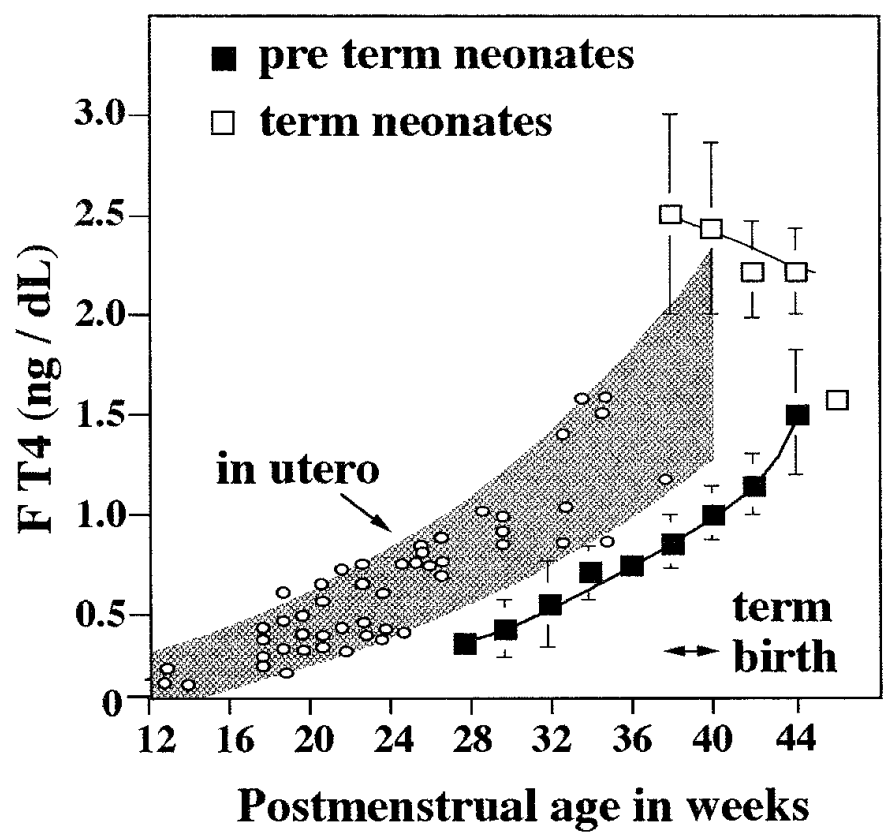

FIG. 7. The mean ( \pm SEM) concentrations of $\mathrm{FT}_{4}$ corresponding to PT and $\mathrm{T}$ neonates in Fig. 5 as a function of PMA are superimposed on data published for fetuses in utero by Thorpe-Beeston et al. (7). The shaded area corresponds to the $95 \%$ confidence intervals for the fetal $\mathrm{FT}_{4}$ data.

below the confidence intervals for the fetal TSH levels, which are clearly higher than those found in T neonates, their mothers, and nonpregnant adults.

\section{Discussion}

\section{I intake}

In a previous study (14) we determined the I content of breast milk, 32 formulas from different brands used in Spain, and 127 formulas from 14 other countries. Breast milk contained more I $(10 \pm 1 \mu \mathrm{g} \mathrm{I} / \mathrm{dL})$ than the majority of formulas, especially those for premature infants. The I content ranged from 1.5-11 $\mu \mathrm{g} \mathrm{I} / \mathrm{dL}$ for the formulas used in Spain and from 2-17 $\mu \mathrm{g} \mathrm{I} / \mathrm{dL}$ for those used in the other countries.

Taking into account the amount of formula and/or breast milk actually ingested by the premature babies, their daily I intake was far below the recommended daily allowance of more than $30 \mu \mathrm{g} \mathrm{I} / \mathrm{kg}$ accepted since 1992 (19) and hardly reached the previous recommendations of $40 \mu \mathrm{g} \mathrm{I} /$ day. The I intake of the $\mathrm{T}$ infants was also clearly lower than the more recently recommended allowance; only a few babies reached a value of $30 \mu \mathrm{g} \mathrm{I} / \mathrm{kg}$ when they were $4-6$ weeks old. Present I intakes are similar to those described for 29 4-week-old PT babies born in Belgium $(20,21)$ and for $\mathrm{T}$ neonates born in France (22).

\section{I excretion and I balance}

The amounts of I excreted by the full-term babies of the present study are similar to those reported by Etlin et al. (22). In the present PT neonates, I excretion changed with PMA, initially decreasing between 27-30 weeks PMA and then increasing steadily. PT and full-term infants of similar PMA excreted the same amounts of I.

Delange et al. $(20,21)$ reported that $40 \%$ of 29 healthy PT babies studied at 34 weeks PMA were in negative I balance. A negative balance was also observed in PT babies of the present study, but was mostly limited to very immature, sick, or SGA infants. The mean weight of the babies studied by the above researchers was $1.75 \pm 0.37 \mathrm{~kg}$, and most of them appeared to have been born at less than 30 weeks GA. Thus, our present findings would confirm this report for such neonates, but not for most of the less immature and healthy PT neonates. Moreover, the present results show that the negative I balance is transient and becomes positive as the PT neonate matures and/or illness is controlled.

Although in most premature neonates both I intake and I excretion increased with PMA, they did so at different rates; the proportion of the ingested I that was not excreted into the urine was not a constant fraction of the intake, with a high degree of individual variability, especially in the younger PT neonates, and increased with age. Considering that excretion of I into the feces represents a minor proportion of excreted I in both PT and T infants $(20,21)$, we have assumed that the positive I balance represents the amount of I that is retained by the neonate. The present results indicate that this capacity appears to be the more limited and variable the younger the 
PT neonate, but that it becomes the same as that in $\mathrm{T}$ infants of comparable I intake and PMA.

The facts that PT and T babies were either in negative or clearly positive I balance and that the proportion of ingested I that is retained is not constant clearly show that their urinary I excretion cannot be equated to their I intake, as usually done in field studies of I nutrition in schoolchildren and adults.

It is very likely that most of the ingested I that is retained (not excreted into urine or feces) is being taken up by the neonate's thyroid gland. It is known that during fetal life the amount of I accumulating in the gland increases steadily as a result of a marked increase in both the weight of the gland and the I uptake $(23,24)$. Thus, a positive I balance would be expected during fetal and early postnatal life and would continue thereafter, as adult glands contain about $10-20 \mathrm{mg}$ $\mathrm{I} /$ gland compared to less than $100 \mu \mathrm{g}$ at T. We do not know at which age the thyroidal I content stabilizes, and intake and excretion become comparable, so that intake may be assessed from urinary I.

It has been suggested (22) that one of the factors leading to the negative I balance of PT babies is the immaturity of their kidneys. Renal immaturity alone, however, does not offer a convincing explanation; unlike other electrolytes, tubular reabsorption of iodide is negligible, and glomerular filtration depends entirely on its circulating concentration (25). Other factors are likely to be involved. Mobilization of previously accumulated I (or thyroid hormone) pools is likely to occur, considering that the loss of I into the urine is greater than its intake. In full term infants neonatal requirements for $\mathrm{T}_{4}$ are quite high: the substitution dose for congenitally hypothyroid neonates is $8-10 \mu \mathrm{g} \mathrm{T}_{4} / \mathrm{kg}$ BW·day compared to approximately $2 \mu \mathrm{g} / \mathrm{kg} \mathrm{BW} \cdot$ day for hypothyroid adults. The dose chosen for $\mathrm{T}_{4}$ treatment of premature babies without congenital hypothyroidism to correct for their hypothyroxinemia is $8 \mu \mathrm{g} \mathrm{T} / 4 / \mathrm{kg} \mathrm{BW} \cdot$ day (26). Deiodination of $\mathrm{T}_{4}$ would represent the release of $12 \mu \mathrm{g} \mathrm{I} /$ day for a PT neonate weighing $2 \mathrm{~kg}$, an amount clearly higher than the I intake of the very immature neonates. Therefore, the negative balance would indicate that the neonates are meeting their hormonal needs by depleting their prenatal intrathyroidal stores. Moreover, the net loss of I into the urine was greater in PTs receiving the higher I intakes, and this suggests that the capacity of the thyroid to accumulate iodide and synthesize $\mathrm{T}_{4}$ is limited, as indicated above.

\section{Parameters of thyroid hormone function}

As prematurity is not a normal physiological situation, circulating levels of $\mathrm{T}_{4}, \mathrm{FT}_{4}, \mathrm{~T}_{3}$, and $\mathrm{TSH}$ are usually compared to those of healthy $\mathrm{T}$ newborns. Our results are in general good agreement with those reported in other studies for both $\mathrm{PT}$ and $\mathrm{T}$ infants. $\mathrm{T}_{4}, \mathrm{FT}_{4}$, and $\mathrm{T}_{3}$ levels are lower in $\mathrm{PT}$ neonates compared to $\mathrm{T}$ newborns, increasing progressively with PMA, whereas TSH levels are the same (27-31). To our knowledge, the possibly independent effects of I intake vs. PT birth on these parameters of thyroid function have not been assessed by others. As indicated previously (14), I intake does affect the circulating levels of $\mathrm{FT}_{4}, \mathrm{~T}_{3}, \mathrm{Tg}$, and TSH in PT infants independently of their PMA. We also show here that premature birth by itself affects $\mathrm{T}_{4}, \mathrm{FT}_{4}$, and Tg independently of I intake and PMA. Circulating levels are lower in PT than in T neonates of comparable PMA and I intake (or balance), at least up to 44 weeks PMA and an intake of $80 \mu \mathrm{g} /$ day. These results also indicate that the thyroid of PT infants is unable to accumulate I or synthesize and/or secrete the same amounts of $\mathrm{T}_{4}$ as that of $\mathrm{T}$ neonates despite equal I intake. Indeed, Van den Hove et al. (32) (personal communication) found that the $\mathrm{Tg}$ content and degree of $\mathrm{Tg}$ iodination in the thyroid of PT babies are low compared to those in T neonates, and the percentage of intrathyroidal I found as $T_{4}$ plus $T_{3}$ is also reduced until they reach a PMA corresponding to normal $\mathrm{T}$. These findings might also explain the lower circulating Tg levels of the PT neonates despite the same degree of thyroid stimulation by comparable levels of circulating TSH.

\section{Proposed interpretation of present results}

Birth severs vascular connections between mother, placenta, and fetus, with sudden interruption of transplacental passage or placental production of nutrients and hormones. The persistent hypothyroxinemia of the PT neonates could be at least partly the result of the premature interruption of the maternal supply of I, thyroid hormone, and placental TRH occurring at a stage of development when the hypothalamicpituitary-thyroid system is not fully mature, and the fetal thyroid is not ready to meet postnatal requirements.

The hypothesis underlying this proposal is that the prolongation of the maternal transfer of thyroid hormone during the second and third trimesters is a physiological event that meets part of the fetal thyroid hormone requirements, permitting the fetal thyroid to mature fully, so as to accumulate I and iodinated $\mathrm{Tg}$, and to produce enough hormone to meet future needs once the maternal supply is interrupted. Premature deprivation of the maternal source of I and thyroid hormone would unduly strain the immature gland of the neonate, and depletion of previous thyroid stores would be a likely consequence. Experimental data obtained in rat fetuses deprived of the maternal supply of thyroid hormone support this possibility; the fetuses manage to meet their extrathyroidal hormone requirements, but do so at the expense of the intrathyroidal stores (33).

$\mathrm{Tg}, \mathrm{T}_{4}$, and $\mathrm{T}_{3}$ are clearly lower in the thyroids of premature infants who survived for a few days or weeks after birth at a mean GA of 35 weeks compared to those of younger aborted fetuses at a mean GA of 22 weeks (34). Such findings may be affected by the pathological process that lead to their death, but the $\mathrm{FT}_{4}$ levels of the present PT infants, many of whom were healthy, were also clearly lower than those reported for fetuses in utero (7), in conceptual agreement with the above findings (34), and the hypothesis proposed here.

TSH is necessary for full maturation of the fetal thyroid, as shown by the atrophy of the gland in cyclocephaly, where the anterior and posterior lobes of the pituitary are absent (35). TSH is positively correlated with $\mathrm{FT}_{4}$ in the fetus, independently of GA, and continues to increase up to term, even when adult $\mathrm{FT}_{4}$ levels have been reached (7). TSH levels in the fetus are much higher than those in $\mathrm{T}$ neonates and adults. As evident when we compared the present results 
with intrauterine TSH levels (7), the high fetal levels drop abruptly with premature birth, and the maturational effects of high serum TSH on the thyroid are thus lost. As shown by the relatively normal pituitary and thyroid development in anencephaly, where hypothalamus and posterior pituitary are absent (35), intrauterine TSH secretion is under the control of extrahypothalamic sources of TRH. High levels of TRH are found in amniotic fluid, when hypothalamic TRH is still low and the hypothalamic-pituitary portal system is not yet fully developed, and in newborns' cord blood $(36,37)$. An important source of TRH that is interrupted at birth is the placenta (38). The sudden decrease in TRH might also have effects other than a decrease in TSH secretion, as neuromodulator functions have been attributed to extrahypothalamic TRH.

The persistent hypothyroxinemia of the premature neonate might also further delay attainment of full thyroid gland maturation by several mechanisms that are not mutually exclusive. In many species thyroid hormones are needed to attain normal concentrations of TRH in the median eminence (39), for differentiation of the preoptic nuclei and hypothalamic-hypophyseal tract (40), and for appearance of monoaminergic axon terminals and penetration of capillaries into the median eminence (41). Such effects of thyroid hormone on the hypothalamic-pituitary portal system might also influence functions other than TSH secretion, including regulation of GH and glucocorticosteroid economy, which would also be affected by premature birth.

\section{Consequences of the proposed interpretation of the present results}

The immediate obvious conclusion regarding interruption of the maternal supply of I is that care should be taken to provide the recommended minimum I intake, so that the external I supply would not be a rate-limiting factor for the synthesis of thyroid hormone once the gland is mature enough to concentrate iodide and incorporate it into thyroid hormone. To assess the I intake, the actual volume of food ingested should be taken into account, not only the I content of the formula preparation. The addition of supplements poses no risk, as there is a wide margin between the recommended I intake and a thyroid-blocking I overload.

Even if the I supply is adequate, it may not be sufficient to avoid the neonatal hypothyroxinemia of premature neonates. Mimicking intrauterine conditions by transient postnatal treatment with $\mathrm{T}_{4}$ might improve some of the thyroidrelated events, such as maturation of thyroidal $\mathrm{T}_{4}$ and $\mathrm{T}_{3}$ synthesis. Van den Hove et al. (personal communication) observed that treatment of the very premature (24-32 weeks GA) PT neonates for 3 days or more with $10 \mu \mathrm{g} \mathrm{T} / \mathrm{kg}$ $\mathrm{BW} \cdot$ day resulted in increases in the degree of iodination of $\mathrm{Tg}$ and the proportion of $\mathrm{I}$ found as $\mathrm{T}_{4}$ and $\mathrm{T}_{3}$, to values similar to those in $\mathrm{T}$ neonates.

Several groups have already performed trials to improve postnatal development of PT neonates with transient postnatal $\mathrm{T}_{4}$ treatment, obtaining either inconclusive or conflicting results. A recent randomized double blind study involving 100 PT neonates of less than 30 weeks GA receiving $8 \mu \mathrm{g}$ $\mathrm{T}_{4} / \mathrm{kg} \cdot$ day for 6 weeks and an equal number receiving pla- cebo has shown that this treatment may improve the developmental outcome measured at $2 \mathrm{yr}$ of age, although the latter beneficial effect is restricted to PT infants of less than 27 weeks GA (26).

As discussed above, postnatal substitution with $\mathrm{T}_{4}$ would compensate for the sudden decrease in $\mathrm{FT}_{4}$ of the premature neonate compared to the $\mathrm{FT}_{4}$ level to which fetal tissues were exposed in utero and may well represent an improvement. However, it would not mimic the intrauterine environment in other aspects, such as the increased serum TRH and TSH levels, which might also contribute to maturation of the hypothalamic-pituitary-thyroid system and other systems involved in brain development. Obviously, more information is needed before such possibilities are considered for clinical trials.

\section{Acknowledgments}

We are grateful to Dr. Marie France van den Hove, Faculté de Médecine, Unité de Biologie Cellulaire, Université Catholique de Louvain (Louvain, Belgium), for permitting us to refer to unpublished results. We are also very grateful to the nurses of the Neonatology Unit of the Hospital Infantil La Paz for careful collection of samples.

\section{References}

1. Contempré B, Jauniaux E, Calvo RM, Jurkovic D, Campbell SM, Morreale de Escobar G. 1993 Detection of thyroid hormone in human embryonic cavities during the first trimester of pregnancy. J Clin Endocrinol Metab. 77:1719-1722.

2. Vulsma T, Gons MH, de Viljder J. 1989 Maternal-fetal transfer of thyroxine in congenital hypothyroidism due to a total organification defect of thyroid agenesis. N Engl J Med. 321:13-16.

3. Calvo RM, Obregón MJ, Ruiz de Oña C, Escobar del Rey F, Morreale de Escobar G. 1990 Congenital hypothyroidism, as studied in rats: crucial role of maternal thyroxine but not of 3,5,3'-triiodothyronine in the protection of the fetal brain. J Clin Invest. 86:889-899.

4. Fisher DA, Dussault JH, Sack J, Chopra IJ. 1977 Ontogenesis of pituitarythyroid function and metabolism in man, sheep and rat. Recent Prog Horm Res. 33:59-116.

5. Morreale de Escobar G, Escobar del Rey F. 1990 Thyroid physiology in utero and neonatally. In: Rubery E, Smales E, eds. Iodine prophylaxis following nuclear accidents. Oxford: Pergamon Press; 3-32.

6. Ballabio M, Nicolini, Jowett T, Ruiz de Elvira MC, Ekins RP, Rodeck CH. 1989 Maturation of thyroid function in normal human foetuses. Clin Endocrinol (Oxf). 31:565-571.

7. Thorpe-Beeston JG, Nicolaides KH, Felton CV, Butler J, McGregor AM. 1991 Maturation of the secretion of thyroid hormone and thyroid-stimulating hormone in the fetus. N Engl J Med. 324:532-536.

8. Delange F, Bourdoux P, Ermans AM. 1985 Transient disorders of thyroid function and regulation in preterm infants. In: Delange F, Fisher DA, Malvoux $\mathrm{P}$, eds. Pediatric thyroidology. Basel: Karger; 369-393.

9. Uhrmann S, Marks KH, Maisels MJ, et al. 1978 Thyroid function in the preterm infant: a longitudinal assesment. J Pediatr. 92:968-973.

10. den Ouden AL, Kok JH, Verkerk PH, Brand R, Verloove-Vanhorick SP. 1996 The relation beteween neontal thyroxine levels and neurodevelopmental out come at age 5 and 9 years in a national cohort of very preterm and/or very low birth weight infants. Pediatr Res. 39:142-145.

11. Reuss ML, Paneth N, Pinto-Martin JA, Lorenz JM, Susser M. 1996 The relation of transient hypothyroxinemia in preterm infants to neurologic development at two years of age. N Engl Med. 334:821-826.

12. Pharoah POD, Buttfield IH, Hetzel B. 1971 Neurological damage to the foetus resulting from severe iodine deficiency during pregnancy. Lancet 1:308-310.

13. Xue-YI C, Xin-Min J, Zhi-Jong D, et al. 1994 Timing of vulnerability of the brain to iodine deficiency in endemic cretinism. N Engl J Med. 331:1739-1744

14. Ares S, Quero J, Durán S, Presas MJ, Herruzo R, Morreale de Escobar G. 1994 Iodine content of infant formulas and iodine intake of premature babies. Arch Dis Child. 71:184-191.

15. Ares S, Pastor I, Quero J, Morreale de Escobar G. 1995 Thyroidal complications, including overt hypothyroidism, related to the use of non-radiopaque silastic catheters for parenteral feeding of prematures, requiring injection of small amounts of an iodinated contrast medium. Acta Paediatr. 84:579-581.

16. Benotti J, Benotti NA. 1963 A semiautomated method for the determination of the plasma PBI. Clin Chem. 9:408-416.

17. Snedecor GW, Cochran WG. 1980 Statistical methods, 7th ed. Ames: Iowa State University Press. 
18. Nelson W E, Behrman RE, Vaughan VC. 1993 Textbook of pediatrics, 14th ed. New York: Saunders.

19. Delange F, Dunn JT, Glinoer D, eds. 1993 Recommendations on iodine nutrition for mothers and infants in Europe. In: Iodine deficiency disorders in Europe: a continuing concern. New York: Plenum Press; 471-478.

20. Delange F. 1985 Physiology of iodine nutrition: trace elements in nutrition of children. In: Chandra RK ed. New York: Nestlé Nutrition, Raven Press; 291-299.

21. Delange F, Dalhem A, Bourdoux P, et al. 1984 Increase risk of primary hypothyroidism in preterm infants. J Pediatr. 105:462-469.

22. Etling N, Padovani E, Gehin-Fouque F, Tato L. 1983 Iodine and thyroid hormone levels in serum and urine of full term newborn infants. Helv Paediatr Acta. 38:117-122.

23. Evans TC, Kretzschmar RM, Hodges RE, Song CW. 1967 Radioiodine uptake studies of the human fetal thyroid. J Nucl Med. 8:157-165.

24. Costa A, De Filippis V, Panizzo M, et al. 1986 Development of thyroid function between VI-IX months of fetal life in humans. J Endocrinol Invest. 9:273-280.

25. Koutras DA. 1986 Iodine distribution, availability and effects of iodine deficiency on the thyroid. In: Dunn JT, Pretell EA, Hernán Daza C, Vitori FE, eds. Towards eradication of goiter, cretinism and iodine deficiency. Washington DC: Pan American Health Organization; 15-27.

26. Van Wassenaer AG, Kok JH, de Vijlder JM, et al. 1997 Effects of thyroxine supplementation on neurologic development in infants born at less than 30 weeks' gestation. N Engl J Med. 336:21-26.

27. Fisher DA, Hobel CJ, Garza R, Pierce CA. 1970 Thyroid function in the preterm fetus. Pediatrics. 46:208-216.

28. Cuestas RA. 1978 Thyroid function in healthy premature infants. J Pediatr. 92:963-967.

29. John R, Bamforth FJ. 1987 Serum free thyroxine and free triiodothyronine concentrations in healthy fullterm, preterm and sick preterm neonates. Ann Clin Biochem. 24:461-465.

30. Kok JH, Tegelaers WHH, De Vijlder JM. 1986 Serum thyoglobulin levels in preterm infants with and without respiratory distress syndrome. A longitudinal study during the first 3 weeks of life. Pediatr Res. 20:1001-1003.
31. De Nayer PH, Cornette C, Vanderschueren M, et al. 1984 Serum thyroglobulin levels in preterm neonates. Clin Endocrinol (Oxf). 21:149-153.

32. Van den Hove MF, De Nayer Ph, Cornette C, Beckers C. 1991 Ontogeny of hormone synthesis and storage in the thyroid of the human fetus and newborn. In: Gordon A, Gross J, Hennemann G, eds. Progress in thyroid research. Rotterdam: Balkema; 631-633.

33. Ruiz de Oña C, Morreale de Escobar G, Calvo RM, Escobar del Rey F, Obregón MJ. 1991 Thyroid hormone and 5' deiodinase in the rat fetus late in gestation: effects of maternal hypothyroidism. Endocrinology. 128:422-432.

34. Savin S, Cvejic D, Mitic N, Sinadinovic J. 1996 Low content of iodothyronines and thyroglobulin in the thyroid gland of human newborn infants. In: Braver man LE, Köhrle J, Eber O, Langsteger W, eds. Thyroid and trace elements. Vienna: Blackwell (CD recording)

35. Toran-Allerand CD. 1986 Normal development of the hypothalamic-pituitary-thyroid axis: ontogeny of the neuroendocrine unit. In: Ingbar SH, Braverman LE, eds. Werner's the thyroid, 5th ed. New York: Lippincott; 7-23.

36. Neary JT, Nakamura C, Davies IJ, Soodak M, Maloof F. 1978 Lower levels of thyrotropin releasing hormone degrading activity in human cord and maternal sera than in the serum of euthyroid, nonpregnant adults. J Clin Invest. 62:1-5.

37. Morley JE, Garvin TJ, Pekary AE, Hershman JM. 1979 Thyrotropin releasing hormone and thyroid hormones in amniotic fluid. Am J Obstet Gynecol. 134:581-584.

38. Shambaugh G, Kubek M, Wilber JF. 1979 Thyrotropin- releasing hormone activity in the human placenta. J Clin Endocrinol Metab. 48:483-486.

39. Mori M, Yamada M. 1987 Thyroid hormones regulate the amount of thyrotropin-releasing hormone in the hypothalamic median eminence of the rat. J Endocrinol. 114:443-448.

40. Gorbman A, Bern HA. 1962 Comparative endocrinology, New York: Wiley and Sons; 366.

41. Kikuyama S, Miyakawa N, Arai Y. 1979 Influence of thyroid hormone on the development of preoptic-hypothalamic monoaminergic neurons in tadpoles of Bufo bufo japonicus. Cell Tissue Res. 198:27-33.

\section{2nd International Congress on Autoimmunity Jerusalem, Israel March 7-12, 1999}

For further information, please contact: Prof. Yehuda Shoenfeld, 2nd International Congress on Autoimmunity, P.O. Box 50006, Tel Aviv 61500, Israel. Tel: 972-3-5-5140000; Fax: 972-3-5175674 or 972-3-5140077; Email: autoim@kenes.com, 